\title{
COUPLING DEGREE MODELING BETWEEN SOIL AND SPECTRAL CHARACTERISTICS OF CROPS BASED ON VEGETATION INDICES AND ENTROPY THEORY
}

\author{
XIANG, M. S. ${ }^{1,2}-$ YANG, W. N. ${ }^{1,2^{*}}-$ YANG, J. ${ }^{1,2}$ \\ ${ }^{1}$ Chengdu University of Technology \\ 610059, Chengdu, Sichuan, P. R. China \\ ${ }^{2}$ Key Laboratory of Geoscience Spatial Information Technology of Ministry of Land and \\ Resources( Chengdu University of Technology) \\ 610059, Chengdu, Sichuan, P. R. China \\ (phone: +86-134-3813-1502) \\ *Corresponding author \\ e-mail: ywn@cdut.edu.cn; phone: +86-137-0800-5934; fax: +86-028-8407-9069
}

(Received $15^{\text {th }}$ Jul 2017; accepted $2^{\text {nd }}$ Nov 2017)

\begin{abstract}
Quantitative inversion of soil quality is a hot topic in soil science and environmental science research, but it is difficult to obtain high-precision soil spectrum information without attachment interference. Therefore, we carried out pot experiment after testing the soil. And then based on the synergistic changes between soil quality and plants, the entropy theory and spectral vegetation indices were used to construct a parameter model of soil environmental factors and plant spectrum at different growth stages with the aid of the spectral integration of hyperspectral imaging and visualization. Parameters of plant spectrum characteristics were used to achieve the goal of indirectly indicating soil quality. The research finds that the characteristic spectral bands of plants lie near 450, 500, 520, 550, 670, 730 and $800 \mathrm{~nm}$. As the plant growth progressed, its spectral reflectivity gradually decreased, the red edge slope and red edge position of plant also manifested a blue shift phenomenon. Inversion is better conducted during the jointing period and MCARI/OSAVI is the optimal vegetation index. The model based on the entropy theory $(r=0.917$, sig $<0.01)$ has higher inversion accuracy than the average spectral vegetation index model $(\mathrm{r}=0.829$, sig $<0.05)$ which indicates that the dual judgment model based on entropy theory and spectral vegetation index better facilitates the remote sensing monitoring research on soil quality. This research is the preliminary application of indirect inversion soil quality and condition through hyperspectral imaging technique and a result from potting and monoculture. Thus, the model still need to be tested further in order to improve its universality.
\end{abstract}

Keywords: soil environmental factors, disaster land, MCARI/OSAVI, hyperspectral imaging, vegetation spectral features

\section{Introduction}

On May 12, 2008 (Beijing time), the Ms8.0 major earthquake occurred in Wenchuan County, Sichuan Province, China. Earthquake and its secondary geological disasters caused damage in 73,300 hectares of cultivated land, loss of 17,700 hectares of arable land and enormous change in soil physicochemical properties and nutrient cycling in Sichuan Province (Yang et al., 2014; Zhong et al., 2016; Ebrahimi et al., 2017; Hejazi et al., 2017). Besides, it resulted in the loss of production capacity of massive cultivated land as well as agricultural use value. Furthermore, it exerts an influence on people's production and life, and restricts the speed of post-disaster recovery and reconstruction. As land is the basis for the survival and development of mankind, to restore and dynamically monitor the resources of lands damaged by disaster is the focus and hotspot of the current research (Yang et al., 2010; Wei et al., 2012; Gao et al., 2017; Hashemi, 
2017). Rapid and accurate grasp of quality conditions of soil in the damaged land is of great significance to adjust and improve the restoration program of damaged lands, the scientific management of land resources, as well as to speed up the pace of post-disaster reconstruction. The traditional soil quality monitoring is mostly carried out by methods such as field sampling and laboratory chemical analysis, etc. Although highly precise, they are time-consuming and costly, unable to monitor dynamically from the macroscopic point of view. However, hyperspectral image technology integrates optics, electronics, information processing with computer science and technology. And combined with the traditional two-dimensional imaging technology and spectral technology, it is characterized by numerous bands, high spectral resolution and imagespectrum emerging, which can directly or indirectly acquire a large number of continuous high-resolution spectral image data, so as to meet the extensity of space and the continuity of time well (Yu, 2012; Hassan et al., 2017; Radan et al., 2017). Hyperspectral imaging stores data in the form of three dimensions, and each pixel is attached to its own spatial location information and single complete radiation or emission spectral information formed by a set of consecutive wavelengths. Based on the spectral information, the physiochemical characteristics of the object can be identified (Ma, 2015). At present, a lot of research results have been achieved on the application of hyperspectral imaging technology in these aspects such as quantitative inversion of soil environmental factors, crop growth monitoring under stress, plant identification and classification and extraction of mineral alteration substance, which provides technical means for dynamic monitoring of soil quality. But these studies mainly focus on the soil in the exposed areas (Vazdani et al., 2017). And the quantitative inversion of the soil environmental condition in the vegetation-covered area is still in the exploratory stage. The main reason is that it is difficult to remove the interference of the attachments when the soil spectrum information is obtained in the vegetation-covered areas and is hard to get the soil spectral information with high-precision (Fernández-Buces et al., 2006; Tilley et al., 2007; Wun et al., 2017).

As the plant leaf tissue changes with the soil nutrient status, biomass and phenological period, spectral characteristics change as well. The spectral reflectance of the plants at $400-700 \mathrm{~nm}, 680-760 \mathrm{~nm}$ and 780-1300 $\mathrm{nm}$ has high correlation with surface index, leaf pigment and substance content (Gu et al., 2008; Xiao et al., 2017), thus the plants physiological parameters have been used to indirectly invert soil indicator factors. Walburg et al. (1982) studied the spectral reflectance characteristics of maize (Zea mays L.) canopy under four different nitrogen stress conditions and found that it is feasible to monitor crop growth through the analysis of maize canopy spectral characteristics. After studying the hyperspectral reflectance, red edge parameters and physiological and ecological parameters of winter wheat (Triticum aestivum L.) under different water stress, found that the red edge area decreased with the increase of drought stress, therefore the hyperspectral characteristics and red edge parameters of winter wheat can help decide the growth of winter wheat and the degree of water stress (Gu et al., 2008). Lu et al. (2007) studied the heavy metal stress of vegetation in Dexing Copper Mine with hyperspectral data. It was found that heavy metal stress caused the phenomenon "red edge" blue shift of vegetation reflectance spectrum. The amount of blue shift is closely related to the degree of heavy metal stress: the more the blue shifts, the more heavy metal content in vegetation canopy there will be and the deeper the vegetation is poisoned. Therefore, the amount of blue shift can indicate the status of soil environmental quality in mining areas. Chen et al. (2012) found that there was a 
difference in the spectral absorption depth of plants under heavy metal stress; therefore, a multiple regression model of heavy metal and absorption depth between 550 and 760 $\mathrm{nm}$ was established (Yang et al., 2017). And they considered it is feasible to use the hyperspectral remote sensing to evaluate the distribution and enrichment of heavy metal elements in vegetation-covered areas. Jia and Zhang (2014) studied the spectral characteristics of sunflowers (Helianthus annuus L.) at different growth periods on soils alkalized to different degrees. According to the study, the reflectance of canopy spectra varied with growth periods. The red edge position and red edge slope showed the blue shift phenomenon as soil alkalinity rose, and the wavelength and amplitude reached the maximum during the flowering period. The correlation coefficient between the red edge position and the soil alkalinity and $\mathrm{pH}$ was 0.768 and 0.681 respectively, which showed a significant positive correlation and the soil alkalization was indicated by the red edge feature of the vegetation spectrum.

A vegetation index is composite spectral information composed of multiple bands, which not only has higher sensitivity than a single band, but also reduces the background error (Zhang et al., 2011). Therefore, vegetation indices have been widely used in the inversion of hyperspectral remote sensing quantification. Bunnik (1978) used a great number of vegetation indices to invert LAI (Leaf Area Index), confirming the possibility of remote sensing technology in extracting vegetation cover and LAI. Zhang et al. (2011) obtained the hyperspectral images of maize in potted trial and in field using near-ground imaging hyperspectral spectrometer, and established the relationship model between vegetation indices of TCARI (Transformed chlorophyll absorption in reflectance index), OSAVI, CARI (chlorophyll absorption in reflectance index) and maize chlorophyll content. The results showed that MCARI/OSAVI was remarkably correlated with chlorophyll content of potted and field maize. Liu et al. (2011) studied the relationship between the spectral vegetation indices of Suaeda salsa and soil chemical properties. It was found that NDVI (Normalized Difference Vegetation Index) could be an elementary indicator of the changes in soil total phosphorus and $\mathrm{pH}$, vegetation indices could well reflect the change of soil salinity's content.

Information entropy is proposed by Shannon in 1948 based on probability theory. It is a measure of the uncertainty of random variables (Shannon 1949). It is widely used in data set segmentation, image quality evaluation, classification decision-making and total pollutant distribution. As a measure of the uncertainty or amount of information of a random variable, the entropy function can be used to calculate the correlation between spatially discrete variables, so as to evaluate the balance of the system. The greater the differences between individuals, the smaller the information entropy and the more imbalanced the system, so information entropy can be used to evaluate crop growth. Influenced by soil environmental factors, crop leaves are a collection of nonequilibrium systems. The worse the soil quality is, the more unstable the crop growth environment will be (Zhang et al., 2005; Wang et al., 2009).

In conclusion, hyperspectral imaging and spectral vegetation index have made a lot of research results in quantitative inversion of soil environmental factors, but the vegetation spectral characteristics are used less to indirectly inverse soil quality and condition and even less especially when combined with remote sensing images after a series of mathematical transformation treatments to indirectly inverse the soil quality. In this paper, the soil samples of regional damaged land were collected from the Duba River basin in Beichuan County, and the contents of $\mathrm{pH}$, available nitrogen, available potassium, available phosphorus and content of organic matter in soil samples were 
analyzed and tested. In addition, the hyperspectral imaging techniques were used to collect maize canopy and single leaf spectral information, based on the "red edge" effect and spectral variation characteristics, the hyperspectral imaging technique was utilized to construct the relationship model of soil environmental factors in disaster-stricken land and crop spectrum characteristics from the perspective of the entropy theory and spectral vegetation indices. Through the analysis of their coupling relationship, this paper tries to indirectly determine the soil environmental quality in disaster-stricken land by means of the physiological characteristics of the crops, which may facilitate rapid and real-time access to the degree of damage so as to offer a study method for the restoration and utilization of disaster-stricken land as well as the soil quality monitoring.

\section{Materials and methods}

\section{Overview of the research area}

Located in the eastern part of Beichuan County and seated in the Longmen Mountains, the Duba River Basin is selected as the typical investigation area (Figure 1).

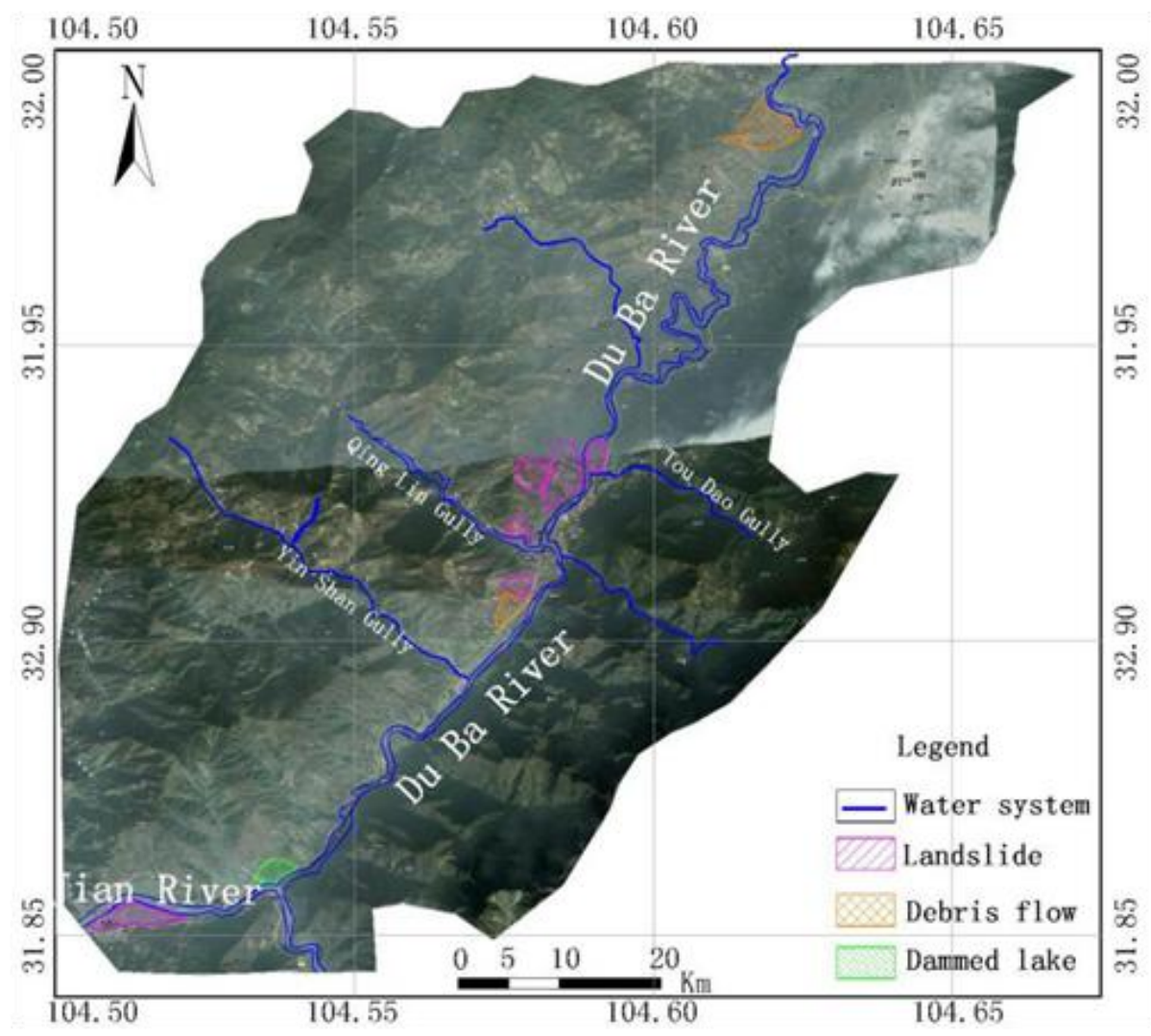

Figure 1. Distribution map of disaster-stricken land. The blue line represents the river distribution, the purple area indicates the land damaged by landslide, the yellow area represents the land damaged by debris flow, the green area represents the land damaged by the barrier lake.

Geographical coordinates are $104^{\circ} 30^{\prime} 37.01^{\prime \prime} \sim 104^{\circ} 37^{\prime} 39.09^{\prime \prime}$ E, $31^{\circ} 51^{\prime} 35.88^{\prime \prime} \sim 31^{\circ}$ $59^{\prime} 30.03 " \mathrm{~N}$. Characterized by high mountains and deep valleys, the territory has complex underlying lithology and geological structure and therefore has strong tectonic 
movements. The study area is mainly mountain, with north subtropical humid monsoon climate. The average temperature for years is $15.6^{\circ} \mathrm{C}$, and the average precipitation is $1300 \mathrm{~mm}$. Vegetation mainly include Cupressus funebris, Pinus massoniana, and Pteridium aquilimum, etc. Soil contains loess, brown earth and yellow brown earth. Crops in this area mainly include maize and Sweet potatoes (Ipomoea batatas L.). Due to the Wenchuan earthquake and secondary geological hazards, multiple landslides, debris flows, dammed lakes, collapse and other geological disasters are distributed across the watershed, which result in serious water loss and soil erosion in this region, also cause bad ecological environment, soil fertility decline, loss of farming ability to some cultivated land, and intense relationship between land and people. This area is seriously affected by Wenchuan earthquake, having the typical and common characteristics of land damaged by disaster, therefore it is chosen as the study area.

\section{Soil sampling and testing}

The checkerboard pattern sampling method is adopted to collect multipoint mixed soil samples along the river basin, including landslides, debris flows and dammed lakes. Table 1 represents the sample location located by GPS.

Table 1. Soil profile and central coordinates in sampling area

\begin{tabular}{c|c|c|c}
\hline Sampling point & Soil texture & Damage type & Central coordinates \\
\hline $1 \#$ & Sandy soil & Landslide & $104^{\circ} 37^{\prime} 9.54^{\prime \prime} \mathrm{E}, 31^{\circ} 59^{\prime} 15.61^{\prime \prime} \mathrm{N}$ \\
$2 \#$ & Sandy soil & Landslide & $104^{\circ} 37^{\prime} 12.09^{\prime \prime} \mathrm{E}, 31^{\circ} 59^{\prime} 16.82^{\prime \prime} \mathrm{N}$ \\
$3 \#$ & Sandy soil & Landslide & $104^{\circ} 37^{\prime} 16.5^{\prime \prime} \mathrm{E}, 31^{\circ} 59^{\prime} 19.05^{\prime \prime} \mathrm{N}$ \\
$4 \#$ & Clay & Landslide & $104^{\circ} 35^{\prime} 31.13^{\prime \prime} \mathrm{E}, 31^{\circ} 56^{\prime} 5.16^{\prime \prime} \mathrm{N}$ \\
$5 \#$ & Clay & Landslide & $104^{\circ} 35^{\prime} 32.04^{\prime \prime} \mathrm{E}, 31^{\circ} 56^{\prime} 17.12^{\prime \prime} \mathrm{N}$ \\
$6 \#$ & Sandy soil & Landslide & $104^{\circ} 35^{\prime} 9.3^{\prime \prime} \mathrm{E}, 31^{\circ} 56^{\prime} 41.44^{\prime \prime} \mathrm{N}$ \\
$7 \#$ & Sandy soil & Landslide & $104^{\circ} 35^{\prime} 14.98^{\prime \prime} \mathrm{E}, 31^{\circ} 56^{\prime} 33.65^{\prime \prime} \mathrm{N}$ \\
$8 \#$ & Clay & Landslide & $104^{\circ} 35^{\prime} 19.89^{\prime \prime} \mathrm{E}, 31^{\circ} 56^{\prime} 33.90^{\prime \prime} \mathrm{N}$ \\
$9 \#$ & Sandy soil & Landslide & $104^{\circ} 34^{\prime} 53.85^{\prime \prime} \mathrm{E}, 31^{\circ} 55^{\prime} 22.31^{\prime \prime} \mathrm{N}$ \\
$10 \#$ & Sandy soil & Landslide & $104^{\circ} 34^{\prime} 55.05^{\prime \prime} \mathrm{E}, 31^{\circ} 55^{\prime} 25.2^{\prime \prime} \mathrm{N}$ \\
$11 \#$ & Sandy soil & Debris flow & $104^{\circ} 34^{\prime} 46.59^{\prime \prime} \mathrm{E}, 31^{\circ} 55^{\prime} 1.04^{\prime \prime} \mathrm{N}$ \\
$12 \#$ & Clay & Debris flow & $104^{\circ} 34^{\prime} 48.72^{\prime \prime} \mathrm{E}, 31^{\circ} 54^{\prime} 46.81^{\prime \prime} \mathrm{N}$ \\
$13 \#$ & Clay & Debris flow & $104^{\circ} 34^{\prime} 40.34^{\prime \prime} \mathrm{E}, 31^{\circ} 54^{\prime} 38.77^{\prime \prime} \mathrm{N}$ \\
$14 \#$ & Sandy soil & Dammed lakes & $104^{\circ} 32^{\prime} 30.97^{\prime \prime} \mathrm{E}, 31^{\circ} 52^{\prime} 16.62^{\prime \prime} \mathrm{N}$ \\
$15 \#$ & Clay & Debris flow & $104^{\circ} 31^{\prime} 19.81^{\prime \prime} \mathrm{E}, 31^{\circ} 51^{\prime} 48.87^{\prime \prime} \mathrm{N}$ \\
$16 \#$ & Clay & Landslide & $104^{\circ} 35^{\prime} 13.75^{\prime \prime} \mathrm{E}, 31^{\circ} 56^{\prime} 9.55^{\prime \prime} \mathrm{N}$ \\
\hline
\end{tabular}

The Analysis and Determination Center of Sichuan Provincial Academy of Agricultural Sciences is entrusted to conduct test for the 5 environmental factors of the soil samples. The available nitrogen is measured with Alkali-diffusion Method according to the forestry industry standards of the People's Republic of China standard LY/T 1228-2015. The available phosphorus is measured by inductively coupled plasma atomic emission spectrometry according to LY/T 1232-2015. The available potassium is measured by atomic absorption spectrophotometer after the sample soil is extracted by ammonium acetate of $1 \mathrm{~mol} / \mathrm{L}$ according to LY/T 1234-2015. The organic matter is measured 
according to NY/T 1121.2-2006: first to oxidize the organic carbon with the excessive potassium dichromate sulfuric acid solution, then to titrate by ferrous sulfate standard solution, so to calculate the amount of organic carbon by the consumption amount of potassium dichromate by oxidation correction coefficient, then to multiply with the constant 1.724. $\mathrm{pH}$ is measured by $\mathrm{pH}$ meter according to NY/T 1121.2-2006 (Table 2).

Table 2. Soil environmental factor content of damaged land

\begin{tabular}{c|c|c|c|c}
\hline Environmental factor & Max & Min & Mean & Standard deviation \\
\hline $\mathrm{pH}-\mathrm{x}_{1}$ & 7.98 & 6.69 & 7.58 & 0.34 \\
Available $\mathrm{N}-\mathrm{x}_{2}(\mathrm{mg} / \mathrm{kg})$ & 151.00 & 15.00 & 56.65 & 40.82 \\
Available $\mathrm{K}-\mathrm{x}_{3}(\mathrm{mg} / \mathrm{kg})$ & 325.00 & 39.20 & 93.25 & 64.06 \\
Available $\mathrm{P}-\mathrm{x}_{4}(\mathrm{mg} / \mathrm{kg})$ & 72.00 & 3.20 & 23.11 & 22.62 \\
DOM- $\mathrm{x}_{5}(\mathrm{~g} / \mathrm{kg})$ & 43.70 & 3.50 & 16.36 & 9.58 \\
\hline
\end{tabular}

\section{Experimental design}

Experimental design is based on improved previous studies (Zhang et al., 2011; Yang et al., 2015). The experiment was carried out in the teaching and research base of the Department of Landscape Architecture in Chengdu University of Technology. First, $\mathrm{pH}$, available nitrogen, available phosphorus, available potassium and dissolved organic matter (DOM), altogether five environmental factor content in the sample soil were measured in the Analysis and Determination Center of Sichuan Academy of Agricultural Sciences (Table 1). Then soil samples of the same quality were taken for the cultivation of potted maize plants, and each soil sample was divided into two, one of which was added with $60 \mathrm{~g}$ of farmyard manure as a control (Zhang et al., 2015), thus total 2 groups (the original group and the control group). Antai 5000 was chosen as the maize variety. In order to eliminate the system error, three maize seeds were planted on each pot, and the planting time was May 17th, 2016. The corn was watered regularly and sprayed pesticides to prevent pests and diseases without any fertilizer in the process of growth. The hyperspectral image data of maize leaves were collected at the jointing period and tasseling period respectively.

\section{Hyperspectral data acquisition and processing}

The spectral data were collected from near-ground imaging by the hyperspectral imaging system of the imaging spectrometer Hyspex of the Norwegian company NEO. The spectral range was 400-1000 $\mathrm{nm}$ and the number of bands was 108. Hyperspectral images of maize canopies and single leaves were collected in two periods (jointing and tasseling). The last three single leaves were collected during the jointing period while the last four were gathered during the tasseling period, producing a total of 128 hyperspectral images.

Since the acquired hyperspectral images were noisy, the original images must be corrected in black and white, and the correction formula is as follows (Eq. l).

$$
R=\frac{R_{i m g}-R_{\text {dark }}}{R_{\text {ref }}-R_{\text {dark }}}
$$


where $R$ is the corrected hyperspectral image, $R_{\text {img }}$ is the original hyperspectral image, $R_{\text {dark }}$ is the black calibration image obtained by turning off the camera lens, and $R_{r e f}$ is the whiteboard calibration image obtained from the standard white calibration plate.

First-order differential processing was applied to the original spectrum, and the formula is as follows (Eq. 2).

$$
\rho^{\prime}=\frac{\mathrm{d} \rho\left(\lambda_{i}\right)}{d \lambda_{i}}=\frac{\rho\left(\lambda_{i+1}\right)-\rho\left(\lambda_{i-1}\right)}{2 \Delta \lambda}
$$

where $i$ is the spectral channel, $\lambda_{i}$ is the wavelength of each band, $\Delta \lambda$ is the interval of wavelength from $\lambda_{i-1}$ to $\lambda_{i}, \rho\left(\lambda_{i}\right)$ is the reflectance of band $\lambda_{i}$, and $\rho^{\prime}$ is the first-order differential spectrum of $\lambda_{i}$.

\section{Information entropy calculation}

Shannon first introduced the concept of entropy into the theory of information and defined it as information entropy. For an uncertain system, $X$ is the state feature. For an discrete random variable, set the value of $x$ as $X=\left\{x_{1}, x_{2}, x_{3}, \ldots x_{n}\right\} \quad(n \geq 2)$, the corresponding probability of each value is denoted by $P, P=\left\{p_{1}, p_{2,}, p_{3, \ldots} p_{\mathrm{n}}\right\} \quad\left(0 \leq p_{i} \leq\right.$ $1, i=1,2,3, \ldots \mathrm{n}$, and $\left.\sum_{i=1}^{n} p_{i}=1\right)$. Then there is the formula (Eq. 3):

$$
S=-\sum_{i=1}^{n} p_{i} \ln p_{i}
$$

\section{Results and discussion}

\section{Analysis of curve spectral characteristics}

The hyperspectral images were processed to derive 64 average hyperspectral curves of 16 groups in two periods. Noise was found in the original spectrum, and it was the most obvious after $900 \mathrm{~nm}$ (Zou et al., 2011). In addition, the edge of the blade would overlap with the background due to the high spectral energy after $850 \mathrm{~nm}$ and supersaturated image information, so the range of the study was determined to be 400$900 \mathrm{~nm}$. Figure $2(a), 2(b)$ are curves of noise reduction and differential treatment of the original spectral curves respectively. Figure $2(a)$ shows a significant reflection peak near 550, 800 and $880 \mathrm{~nm}$, a significant absorption valley near 670 and $820 \mathrm{~nm}$, a sharp rise in reflectance between 670 and $750 \mathrm{~nm}$, and a higher overall reflectance after 750 $\mathrm{nm}$. These kinds of conclusions are also found in the research on pumpkin (Cucurbita moschata) leaves by Zhao et al. (2014). Fig. 2 (b) shows that during the jointing period, there are reflection peaks near 450,520,600,730 and $850 \mathrm{~nm}$, especially in the vicinity of 520 and $700 \mathrm{~nm}$ while there are three absorption valleys near 580, 655 and $810 \mathrm{~nm}$. During the tasseling period, there is no obvious reflection peak near 450 and $850 \mathrm{~nm}$, the absorption valley at $810 \mathrm{~nm}$ also disappears. 


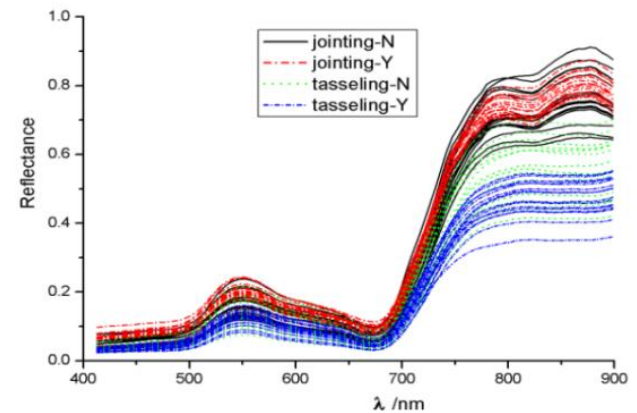

(a) The original spectral reflectance curve of blade

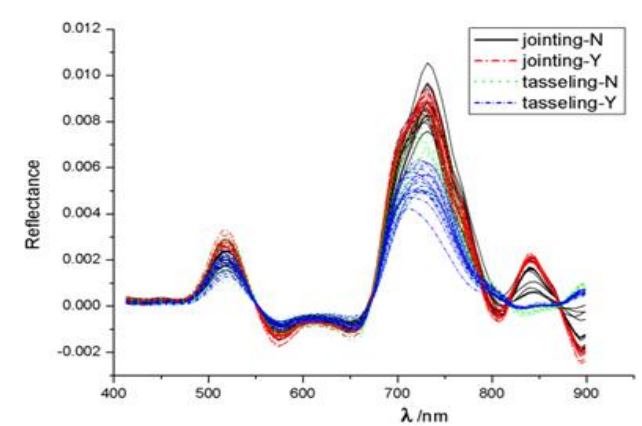

(b) First-order differential reflectance curve of blade

Figure 2. Spectral reflectance curve of blade during jointing and tasseling. The black line indicates the spectral curve of unfertilized corn leaves in the jointing stage jointing- $N$. the red one represents the spectral curve of fertilized corn leaves in the jointing stage jointing-Y. the green one demonstrates the spectral curve of unfertilized corn leaves in the tasseling stage tasseling- $N$. and the blue one represents the spectral curve of fertilized corn leaves in the tasseling stage tasseling- $Y$.

A comparison of the four groups of spectral curves during the two periods (jointing period fertilization group and non-fertilization group, tassel period fertilization group and non-fertilization group are represented by jointing-Y, jointing-N, tasseling-Y and tasseling- $\mathrm{N}$, respectively) revealed that during the jointing period, the reflectance of the fertilization group was significantly higher than that of the untreated group, especially after $730 \mathrm{~nm}$, while the difference was less obvious during the tasseling period. The "red edge" position in the first-order differential spectrum was found near $730 \mathrm{~nm}$, and the red edge position as well as the red edge slope of the tasseling period showed a significant blue shift.

Figure $3(a)$ is a selection of maize leaves of different growth conditions (or morbid leaves) at different periods and different leaf positions in different soil environments. Figure $3(b)$ and Figure $3(c)$ are corresponding reflectance curves and first-order differential transformation spectral curves. By comparison we found that the reflection peak near $450 \mathrm{~nm}$ and the absorption valley near $800 \mathrm{~nm}$ has disappeared. The worse the crop grows, the more gentle the curve near 550-670 $\mathrm{nm}$ is with no obvious reflection peak, in the 670-740 nm "red edge" rising area, the less obvious the red edge feature is with obvious blue-shift phenomenon, which is mainly due to differences in chlorophyll content. A composite analysis of Figure 2 and Figure 3 shows that the relevant bands may be near 450, 500, 520, 550, 670, 730 and $800 \mathrm{~nm}$.
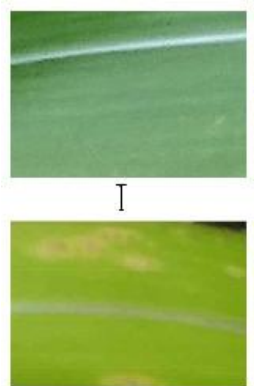

VII

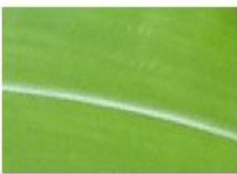

II

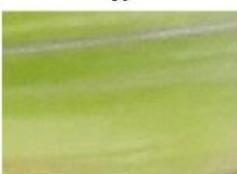

VIII

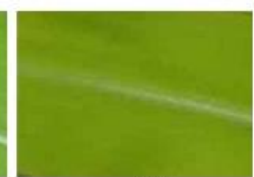

III

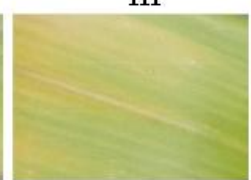

IX

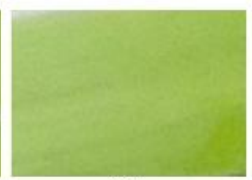

IV

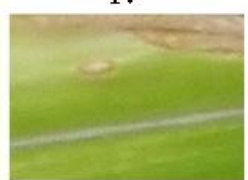

X

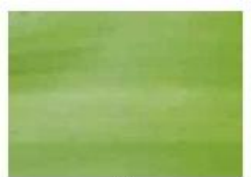

V

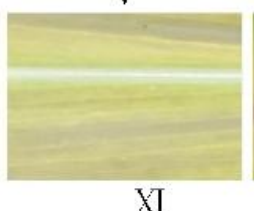

$\mathrm{XT}$

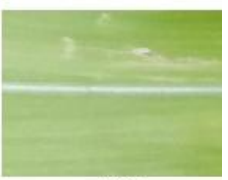

$\mathrm{VT}$

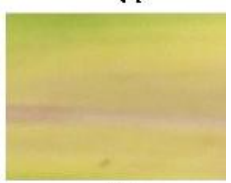

XII

(a) Leaves of different conditions 


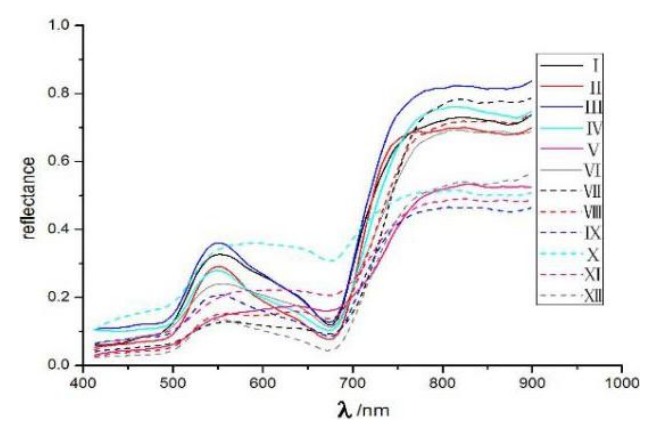

(b) The original spectral reflectance curve of leaves with different conditions

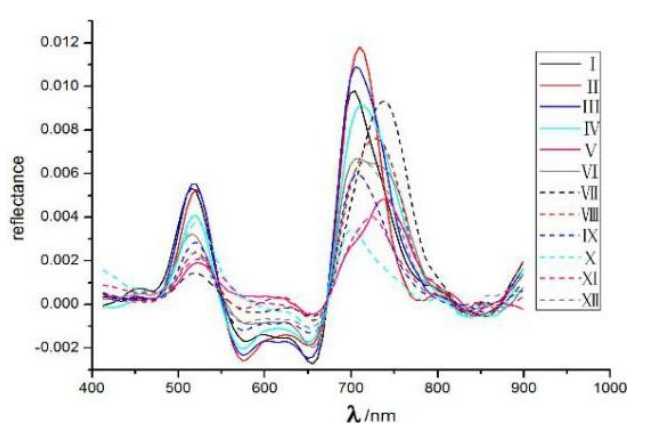

(c) First-order differential reflectance curve of leaves with different conditions

Figure 3. Comparison of spectral reflectance of leaves in different conditions. Curves I-XII. in Figure $(b, c)$ are the original and first-order differential spectral curves corresponding to the leaves I-XII. in Figure (a).

\section{Analysis of the correlation between average spectral vegetation indices and soil environmental factors}

After reviewing the relevant literature and analyzing characteristic bands, six vegetation indices with better predictive effects were preliminarily screened from multiple spectral vegetation indices for the study, as shown in Table 3.

Table 3. Spectral vegetation indices and references

\begin{tabular}{c|c|c}
\hline NO. & vegetation indices & Reference \\
\hline 1 & $\operatorname{NDVI}\left(\mathrm{y}_{1}\right)=\left(\mathrm{R}_{800}-\mathrm{R}_{670}\right) /\left(\mathrm{R}_{800}+\mathrm{R}_{670}\right)$ & Buschmann and Nagel, 1993 \\
2 & $\operatorname{SIPI}\left(\mathrm{y}_{2}\right)=\left(\mathrm{R}_{800}-\mathrm{R}_{450}\right) /\left(\mathrm{R}_{800}+\mathrm{R}_{450}\right)$ & Penuelas et al., 1995 \\
3 & $\operatorname{PRI}\left(\mathrm{y}_{3}\right)=\left(\mathrm{R}_{550^{-}}-\mathrm{R}_{531}\right) /\left(\mathrm{R}_{550}+\mathrm{R}_{531}\right)$ & Gamon et al., 1992 \\
4 & $\operatorname{MTCI}\left(\mathrm{y}_{4}\right)=\left(\mathrm{R}_{753.75}-\mathrm{R}_{708.75}\right) /\left(\mathrm{R}_{708.75}-\mathrm{R}_{681.25}\right)$ & Dash and Curran, 2004 \\
5 & $\operatorname{PSNDa}\left(\mathrm{y}_{5}\right)=\left(\mathrm{R}_{800^{-}}-\mathrm{R}_{680}\right) /\left(\mathrm{R}_{800}+\mathrm{R}_{680}\right)$ & Blackburn, 1998 \\
6 & $\operatorname{MCARI} / \mathrm{OSAVI}\left(\mathrm{y}_{6}\right)=\left[\left(\mathrm{R}_{700}-\mathrm{R}_{670}\right)-0.2 \times\left(\mathrm{R}_{700^{-}}\right.\right.$ & \\
& $\left.\left.\mathrm{R}_{550}\right)\right] \times\left(\mathrm{R}_{700} / \mathrm{R}_{670}\right) /\left[1.16 \times\left(\mathrm{R}_{800}-\mathrm{R}_{670}\right) /\left(\mathrm{R}_{800}+\mathrm{R}_{670}+0.16\right)\right]$ & Daughtry et al., 2000 \\
\hline
\end{tabular}

Linear regression models of each vegetation index and soil environmental factors show that the correlation between a single environmental factor and vegetation index is small, and it is difficult to quantitatively invert or indicate the content of some soil environmental factor through vegetation indices. However, the correlation between the five environmental factors and vegetation indices is greatly improved, and it is proved that the crop growth is not controlled by a certain environmental factor, but is the result of the interaction of various environmental factors, as shown in Table 4.

It can be seen From Table 4 that the correlation between vegetation indices and soil environmental factors during the jointing period was the highest, and the correlation between improved groups was low, indicating that fertilization affects the crop growth by changing the environment and thus changes the physiological spectrum of the crop. but the difference between jointing period and tassel period is obvious, which is similar to the results of the researches by others (Yang et al., 2017; Pan et al., 2015). The correlation during the jointing period was higher than that of the tasseling period, mainly because as the crop growth progresses, the demand for nutrients increases while 
nutrients in the soil are reduced, meanwhile, the effects of other factors in the growing environment play an increasingly significant role, leading to crop morbidity. The three vegetation indices of SIPI (Structure Insensitive Pigment Index), MTCI (MERIS terrestrial chlorophyll index) and MCARI/OSAVI were best correlated with soil environmental factors, and the correlation coefficient $r$ was $0.812,0.823$ and 0.829 respectively, especially for non-fertilization group during the jointing period at a level of 0.05 . Therefore, the three vegetation indices were identified as the optimal vegetation indices for further study.

Table 4. Coupling relationship model and evaluation of average spectral vegetation indices and environmental factors

\begin{tabular}{|c|c|c|c|c|}
\hline $\begin{array}{c}\text { Vegetation } \\
\text { indices }\end{array}$ & $\begin{array}{c}\text { Growing } \\
\text { period }\end{array}$ & $\mathbf{r}$ & Linear regression model & Sig. \\
\hline \multirow{4}{*}{$\operatorname{NDVI}\left(\mathrm{y}_{1}\right)$} & Jointing-N & 0.581 & $\mathrm{y}_{1}=-0.002 \mathrm{x}_{1}-0.007 \mathrm{x}_{2}-3.838 \times 10^{-5} \mathrm{x}_{4}+0.036 \mathrm{x}_{5}+0.849$ & 0.456 \\
\hline & Jointing-Y & 0.475 & $\mathrm{y}_{1}=0.003 \mathrm{x}_{1}+0.005 \mathrm{x}_{2}-0.02 \mathrm{x}_{5}+0.775$ & 0.714 \\
\hline & Tasseling-N & 0.611 & $\mathrm{y}_{1}=0.022 \mathrm{x}_{1}-0.004 \mathrm{x}_{2}+0.04 \mathrm{x}_{5}+0.66$ & 0.38 \\
\hline & Tasseling-Y & 0.502 & $\mathrm{y}_{1}=0.022 \mathrm{x}_{1}-6.637 \times 10^{-5} \mathrm{x}_{2}+0.001 \mathrm{x}_{4}+0.015 \mathrm{x}_{5}+0.659$ & 0.652 \\
\hline \multirow{4}{*}{$\operatorname{SIPI}\left(\mathrm{y}_{2}\right)$} & Jointing-N & 0.812 & $y_{2}=-0.003 x_{1}-2.34 \times 10^{-7} x_{2}+8.99 \times 10^{-5} x_{3}+5.94 \times 10^{-5} x_{4}-0.003 x_{5}+0.85$ & 0.033 \\
\hline & Jointing-Y & 0.745 & $\mathrm{y}_{2}=-0.003 \mathrm{x}_{1}+4.6 \times 10^{-5} \mathrm{x}_{2}-3.94 \times 10^{-5} \mathrm{x}_{3}-1.54 \times 10^{-6} \mathrm{x}_{4}-0.001 \mathrm{x}_{5}+1.05$ & 0.103 \\
\hline & Tasseling-N & 0.566 & $\mathrm{y}_{2}=-0.001 \mathrm{x}_{1}+0.001 \mathrm{x}_{2}+5.08 \times 10^{-5} \mathrm{x}_{3}+6.89 \times 10^{-5} \mathrm{x}_{4}-0.008 \mathrm{x}_{5}+1.03$ & 0.494 \\
\hline & Tasseling-Y & 0.567 & $\mathrm{y}_{2}=-0.006 \mathrm{x}_{1}-2.965 \times 10^{-5} \mathrm{x}_{2}-0.004 \mathrm{x}_{5}+1.072$ & 0.492 \\
\hline \multirow{4}{*}{$\operatorname{PRI}\left(\mathrm{y}_{3}\right)$} & Jointing-N & 0.47 & $\mathrm{y}_{3}=-0.005 \mathrm{x}_{1}+2.327 \times 10^{-5} \mathrm{x}_{3}-1.843 \times 10^{-5} \mathrm{x}_{4}+0.001 \mathrm{x}_{5}+0.850$ & 0.723 \\
\hline & Jointing-Y & 0.684 & $\mathrm{y}_{3}=-0.001 \mathrm{x}_{1}+4.636 \times 10^{-5} \mathrm{x}_{3}-3.759 \times 10^{-5} \mathrm{x}_{4}-0.002 \mathrm{x}_{5}+0.038$ & 0.209 \\
\hline & Tasseling-N & 0.186 & $\mathrm{y}_{3}=5.94 \times 10^{-8} \mathrm{x}_{3}-3.451 \times 10^{-5} \mathrm{x}_{4}-0.001 \mathrm{x}_{5}+0.052$ & 0.995 \\
\hline & Tasseling-Y & 0.234 & $\mathrm{y}_{3}=-0.003 \mathrm{x}_{1}+1.62 \times 10^{-5} \mathrm{x}_{2}-1.6 \times 10^{-5} \mathrm{x}_{3}-1.91 \times 10^{-5} \mathrm{x}_{4}+0.001 \mathrm{x}_{5}+0.034$ & 0.986 \\
\hline \multirow{4}{*}{$\operatorname{MTCI}\left(\mathrm{y}_{4}\right)$} & Jointing-N & 0.823 & $y_{4}=-0.09 x_{1}-0.08 x_{2}-0.003 x_{3}-0.001 x_{4}+0.479 x_{5}+2.909$ & 0.025 \\
\hline & Jointing-Y & 0.499 & $\mathrm{y}_{4}=0.186 \mathrm{x}_{1}+0.025 \mathrm{x}_{2}-0.015 \mathrm{x}_{5}+0.515$ & 0.66 \\
\hline & Tasseling-N & 0.719 & $\mathrm{y}_{4}=0.644 \mathrm{x}_{1}-0.114 \mathrm{x}_{2}-0.007 \mathrm{x}_{3}-0.003 \mathrm{x}_{4}+0.986 \mathrm{x}_{5}-2.8927$ & 0.143 \\
\hline & Tasseling-Y & 0.643 & $\mathrm{y}_{4}=0.123 \mathrm{x}_{1}+8.173 \times 10^{-5} \mathrm{x}_{2}-0.004 \mathrm{x}_{3}+0.009 \mathrm{x}_{4}+0.115 \mathrm{x}_{5}+1.179$ & 0.3 \\
\hline \multirow{4}{*}{$\operatorname{PSND}_{\mathrm{a}}\left(\mathrm{y}_{5}\right)$} & Jointing-N & 0.592 & $\mathrm{y}_{5}=-0.002 \mathrm{x}_{1}-0.007 \mathrm{x}_{2}+3 \times 10^{-5} \mathrm{x}_{4}+0.036 \mathrm{x}_{5}+0.833$ & 0.427 \\
\hline & Jointing-Y & 0.501 & $\mathrm{y}_{5}=-0.022 \mathrm{x}_{1}+0.001 \mathrm{x}_{4}+0.015 \mathrm{x}_{5}+0.652$ & 0.655 \\
\hline & Tasseling-N & 0.611 & $\mathrm{y}_{5}=0.022 \mathrm{x}_{1}-0.004 \mathrm{x}_{2}+0.039 \mathrm{x}_{5}+0.657$ & 0.38 \\
\hline & Tasseling-Y & 0.501 & $\mathrm{y}_{5}=0.022 \mathrm{x}_{1}-7.662 \times 10^{-5} \mathrm{x}_{2}+0.001 \mathrm{x}_{4}+0.015 \mathrm{x}_{5}+0.652$ & 0.655 \\
\hline \multirow{4}{*}{$\begin{array}{c}\text { MCARI/OSAVI } \\
\left(\mathrm{y}_{6}\right)\end{array}$} & Jointing-N & 0.829 & $y_{6}=0.004 x_{1}+0.001 x_{2}+4.26 \times 10^{-4} x_{3}+6.299 \times 10^{-5} x_{4}-0.065 x_{5}+0.228$ & 0.022 \\
\hline & Jointing-Y & 0.6 & $\mathrm{y}_{6}=-0.045 \mathrm{x}_{1}+0.001 \mathrm{x}_{2}-0.016 \mathrm{x}_{5}+0.665$ & 0.407 \\
\hline & Tasseling-N & 0.713 & $\mathrm{y}_{6}=-0.056 \mathrm{x}_{1}+0.014 \mathrm{x}_{2}+0.001 \mathrm{x}_{4}-0.108 \mathrm{x}_{5}+0.207$ & 0.154 \\
\hline & Tasseling-Y & 0.597 & $\mathrm{y}_{6}=-0.01 \mathrm{x}_{5}+0.235$ & 0.415 \\
\hline
\end{tabular}

\section{Image visualization and analysis}

Band Math of ENVI was used for band operations and the results were graded according to Table 5, and leaf visualization distribution was generated through the image processing technology. As shown in Figure 4, the grading distribution of SIPI were more disorderly with an overall lower grade on the left side of the veins and the leaf edge while a higher grade on the right side, the whole leaves were dominated by 
grade 4, MTCI presented an upgrade from the blade edge to the center area with more distinctive leaf grade distribution, and most parts were classified as grade 5 .

Table 5. Grading table of vegetation indices

\begin{tabular}{c|c|c|c|c|c}
\hline \multirow{2}{*}{ Vegetation indices } & \multicolumn{5}{|c}{ Grade } \\
\cline { 2 - 6 } & $\mathbf{1}$ & $\mathbf{2}$ & $\mathbf{3}$ & $\mathbf{4}$ & $\mathbf{5}$ \\
\hline SIPI & $<1.00$ & $1.00 \sim 1.05$ & $1.05 \sim 1.10$ & $1.10 \sim 1.15$ & $>1.15$ \\
MTCI & $<4.06$ & $4.06 \sim 7.52$ & $7.52 \sim 10.98$ & $10.98 \sim 14.44$ & $>14.44$ \\
MCARI/OSAVI & $<0.17$ & $0.17 \sim 0.28$ & $0.28 \sim 0.39$ & $0.39 \sim 0.50$ & $>0.50$ \\
\hline
\end{tabular}

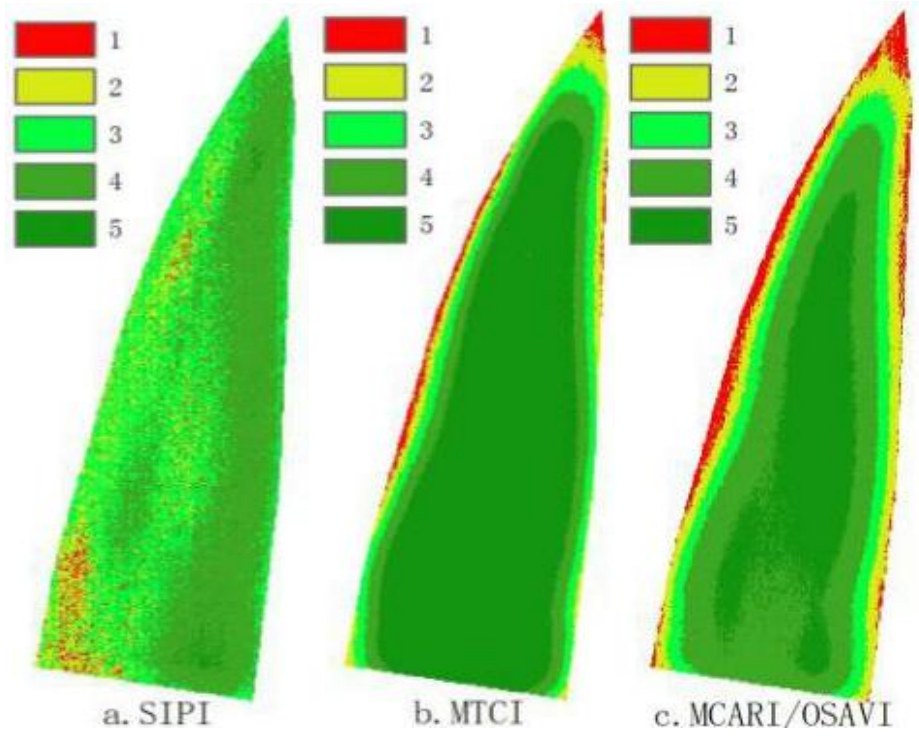

Figure 4. Comparison of classification results. The following are three grading results comparison figures: $a$. the grading results through band operation by SIPI; $b$. the grading results through band operation by MTCI; c. the grading results through band operation by MCARI/OSAVI.

When studying the chlorophyll content in the leaves of cucumber (Cucumis sativus L.) and pumpkin, other scholars found that the chlorophyll content in the leaf edge was significantly lower than that in other regions. More healthy the leaves are, more uniform the chlorophyll distributes (Zhou et al., 2014). MCARI/OSAVI had certain similarities with MTCI such as clearer distribution, lower grade on the blade edge, higher grade at the center yet dominated by grade 4 and 5. Finally, the ENVI tools were used for statistics of all grades.

\section{Correlation analysis of entropy and soil environmental factors}

Calculate the entropy $(S)$ of each group, as shown the results in Table 6, the entropy values varied with growth periods. The standard deviation of the fertilization group was lower than that of the non-fertilization group based on the three vegetation indices, indicating that differences of spectral reflectance among the fertilization group was smaller. Changes in soil environmental factor content have an effect on crop growth process, which can be well indicated by the differences in spectral characteristics and entropy. 
Table 6. Calculation results of $S$

\begin{tabular}{c|c|c|c|c|c}
\hline Vegetation indices & Growing period & Max & Min & Mean & $\begin{array}{c}\text { Standard } \\
\text { deviation }\end{array}$ \\
\hline \multirow{3}{*}{ SIPI } & Jointing-N & 0.686 & 0.172 & 0.382 & 0.140 \\
& Jointing-Y & 1.088 & 0.486 & 0.754 & 0.102 \\
& Tasseling-N & 1.108 & 0.415 & 0.806 & 0.195 \\
& Tasseling-Y & 2.112 & 0.576 & 0.975 & 0.168 \\
& Jointing-N & 0.950 & 0.365 & 0.657 & 0.151 \\
MTCI & Jointing-Y & 0.600 & 0.300 & 0.429 & 0.102 \\
& Tasseling-N & 1.469 & 0.654 & 0.910 & 0.210 \\
& Tasseling-Y & 1.121 & 0.523 & 0.728 & 0.168 \\
& Jointing-N & 2.318 & 2.107 & 2.239 & 0.057 \\
MCARI/OSAVI & Jointing-Y & 2.301 & 2.022 & 2.216 & 0.046 \\
& Tasseling-N & 2.302 & 1.840 & 2.146 & 0.129 \\
& Tasseling-Y & 2.299 & 1.860 & 2.100 & 0.125 \\
\hline
\end{tabular}

The linear regression model of entropy and soil environmental factors was established, as shown in Table 7, the correlation between crop spectral characteristics and soil environmental factors based on entropy principle was higher than that calculated in Table 4, MCARI/OSAVI, in particular, reached 0.917 ( $\mathrm{Sig}<0.01$ ), much greater than the previous 0.829 and more stable. In the study of the relation between maize chlorophyll and spectral vegetation indices, it is found that MCARI/OSAVI is the best vegetation indices in modeling (Zhang et al., 2011). Based on all of the three vegetation indices, the correlation between jointing- $\mathrm{N}$ and the soil environmental factors was higher than that of other groups, which is in agreement with the analysis results in Results section, indicating that the jointing period is the best inversion period. $\mathrm{pH}$, available nitrogen and organic matter are most closely related to crop growth according to the correlation model.

Table 7. Correlation model and assessment of $S$ and soil environmental factors

\begin{tabular}{|c|c|c|c|c|}
\hline $\begin{array}{l}\text { Vegetation } \\
\text { indices }\end{array}$ & $\begin{array}{l}\text { Growing } \\
\text { period }\end{array}$ & $\mathbf{r}$ & Linear regression model & Sig. \\
\hline \multirow{4}{*}{ SIPI } & Jointing-N & 0.824 & $y_{1}=0.023 x_{1}+0.004 x_{2}+0.002 x_{3}+2.84 \times 10^{-4} x_{4}-0.023 x_{5}+0.187$ & 0.025 \\
\hline & Jointing-Y & 0.386 & $\mathrm{y}_{1}=-0.002 \mathrm{x}_{1}-0.001 \mathrm{x}_{2}+0.013 \mathrm{x}_{5}+0.7$ & 0.870 \\
\hline & Tasseling- $\mathrm{N}$ & 0.764 & $\mathrm{y}_{1}=-0.023 \mathrm{x}_{1}+0.003 \mathrm{x}_{2}+0.005 \mathrm{x}_{4}-0.016 \mathrm{x}_{5}+1.022$ & 0.077 \\
\hline & Tasseling-Y & 0.359 & $\mathrm{y}_{1}=-0.223 \mathrm{x}_{1}+0.002 \mathrm{x}_{2}+0.001 \mathrm{x}_{3}-0.005 \mathrm{x}_{4}-0.014 \mathrm{x}_{5}+2.803$ & 0.904 \\
\hline \multirow{4}{*}{ MTCI } & Jointing-N & 0.758 & $Y_{4}=-0.235 x_{1}-0.004 x_{2}-9.09 \times 10^{-4} x_{3}+4.06 \times 10^{-4} x_{4}+0.015 x_{5}+2.555$ & 0.085 \\
\hline & Jointing-Y & 0.495 & $\mathrm{Y}_{4}=0.025 \mathrm{x}_{1}+0.002 \mathrm{x}_{4}-0.001 \mathrm{x}_{5}+0.242$ & 0.668 \\
\hline & Tasseling-N & 0.721 & $Y_{4}=0.023 x_{1}-0.005 x_{2}-0.003 x_{3}-9.271 \times 10^{-5} x_{4}+0.03 x_{5}+0.769$ & 0.139 \\
\hline & Tasseling-Y & 0.629 & $\mathrm{Y}_{4}=-0.249 \mathrm{x}_{1}-0.002 \mathrm{x}_{2}-2.312 \times 10^{-5} \mathrm{x}_{3}+0.007 \mathrm{x}_{4}-0.006 \mathrm{x}_{5}+2.673$ & 0.127 \\
\hline \multirow{4}{*}{ MCARI/OSAVI } & Jointing-N & 0.917 & $Y_{6}=0.081 x_{1}+0.002 x_{2}+4.26 \times 10^{-4} x_{3}-4.42 \times 10^{-4} x_{4}-0.008 x_{5}+1.618$ & 0.001 \\
\hline & Jointing-Y & 0.575 & $\mathrm{Y}_{6}=-0.042 \mathrm{x}_{1}+1.772 \times 10^{-5} \mathrm{x}_{4}+0.003 \mathrm{x}_{5}+2.56$ & 0.472 \\
\hline & Tasseling-N & 0.660 & $\mathrm{Y}_{6}=0.014 \mathrm{x}_{1}+0.003 \mathrm{x}_{2}+0.002 \mathrm{x}_{3}-0.002 \mathrm{x}_{4}-0.014 \mathrm{x}_{5}+2.018$ & 0.262 \\
\hline & Tasseling-Y & 0.652 & $\mathrm{Y}_{6}=0.134 \mathrm{x}_{1}-0.002 \mathrm{x}_{2}+0.001 \mathrm{x}_{3}-0.004 \mathrm{x}_{4}+0.008 \mathrm{x}_{5}+0.992$ & 0.280 \\
\hline
\end{tabular}


Figure 5 is the linear fitting of Soil Environmental Composite Index (SECI) and entropy $(S)$ according to the correlation model during the jointing period based on vegetation index MCARI/OSAVI with a calculated correlation of 0.917 . It can be seen that the composite index of soil environmental factors was positively correlated with the entropy. The maximum composite index was 2.312 when the corresponding $\mathrm{pH}$ of the soil samples was 7.49, the optimum $\mathrm{pH}$ value of crop growth, and the remaining four soil environmental factors were $151,325,72 \mathrm{mg} / \mathrm{kg}$ and $43.7 \mathrm{~g} / \mathrm{kg}$ respectively, all reaching the respective maximum in collected soil samples, and the soil fertility levels reached the first grade. The minimum composite index was 2.126 when the corresponding $\mathrm{pH}$ of soil samples was 6.85 , meeting the $\mathrm{pH}$ requirements for crop growth as well, but the other four soil environmental factors were $21,97.8,2.6 \mathrm{mg} / \mathrm{kg}$ and $15.9 \mathrm{~g} / \mathrm{kg}$ respectively, smaller than other soil samples, and soil fertility levels were classified as grade IV. The comparison of the entropy, soil environmental composite index and contents of five soil environmental factors once again proves that the crop spectrum vegetation indices are more accurate in indicating soil quality in disasterstricken land.

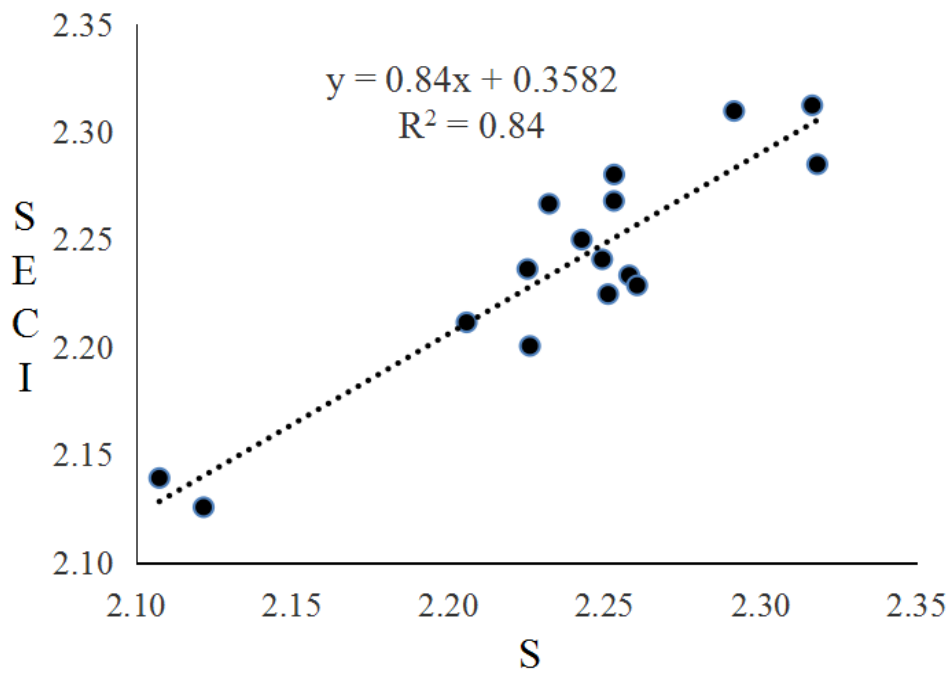

Figure 5. Linear fitting of entropy $S$ and SECI

\section{Conclusions}

Through the analysis of original reflectivity spectral curves and first-order differential spectral curves, we found that the characteristic spectral bands of the crop were near 450, 500, 520, 550, 670, 730 and $800 \mathrm{~nm}$, and the red edge was near $730 \mathrm{~nm}$. As the crop growth progressed, its spectral reflectivity gradually decreased, and the red edge position together with red edge slope of crop showed a blue shift phenomenon. Taking characteristic spectral bands into consideration, six vegetation indices, such as SIPI and MCARI/OSAVI, were selected to establish the linear regression model of average spectral vegetation index and soil environmental factors, and the differences between the fertilization group and the non-fertilization group were significant, which indicates that the physiological characteristics of the crop were related to the soil environmental factors. The correlation coefficients of the three average spectral vegetation indices of SIPI, MTCI and MCARI/OSAVI in jointing-N group were 0.812 , 0.823 and 0.829 , respectively, pointing to a high coupling degree. Based on the entropy 
theory, a linear regression model of entropy and soil environmental factors was constructed by using visualization technology to generate pseudo-color vane images from which we learn that MCARI/OSAVI is the optimal vegetation index, and the model based on the entropy theory $(r=0.917$, sig $<0.01)$ has higher inversion accuracy than the widely used average spectral vegetation index model $(r=0.829$, sig < 0.05$)$. Then the SECI-S linear regression model was further established and verified against the measured values one by one. It was found that the SECI was positively correlated with the $S$, and the predicted results were highly coupled with the actual condition of soil quality. Therefore, the model based on the entropy theory is more accurate, which may well contribute to the study of indirect indication of soil quality through crop physiological spectral variations. The study is based on the double decision model of entropy theory and the spectral vegetation indices, employing the hyperspectral imaging techniques to indirectly invert the soil quality, which is different from the previous research methods. But the result is deduced from potting and single crop varieties, so the model needs to be tested in field experiments and multiple crop varieties to improve the universality of the model. We hope to expand the advantages of the application of hyperspectral imaging in soil quality monitoring in the following study, to serve the agricultural production and post-disaster reconstruction.

Acknowledgements. This research was financially supported by the National Natural Science Foundation of China (Grant No.41372340 and No.41671432). The authors appreciate the valuable comments from anonymous reviewers.

\section{REFERENCES}

[1] Bunnik, N. J. J. (1978): The Multispectral Reflectance of Shortwave Radiation by Agricultural Crops in Relation with Their Morphological and Optical Properties. Landbouwhoge School, Wageningen, Netherlands.

[2] Chen, S. B., Zhou, C., Wang, J. N. (2012): Vegetation stress spectra and their relations with the contents of metal elements within the plant leaves in metal mines in Heilongjiang. - Spectroscopy and Spectral Analysis 32(5): 1310-1315.

[3] Daughtry, C. S. T., Walthall, C. L., Kim, M. S., Colstoun, E. B. D., Iii, M. M. (2000): Estimating corn leaf chlorophyll concentration from leaf and canopy reflectance. Remote Sensing of Environment 74(2): 229-239.

[4] Ebrahimi, N., Gharibreza, M., Hosseini, M., Ashraf, M. A. (2017): Experimental study on the impact of vegetation coverage on flow roughness coefficient and trapping of sediment. - Geology, Ecology, and Landscapes 1(3): 167-172.

[5] Fernández-Buces, N., Siebe, C., Cram, S., Palacio, J. L. (2006): Mapping soil salinity using a combined spectral response index for bare soil and vegetation: a case study in the former lake Texcoco, Mexico. - Journal of Arid Environments 65(4): 644-667.

[6] Gao, W., Rajesh Kanna, M. R., Suresh, E., Farahani, M. R. (2017): Calculating of degreebased topological indices of nanostructures. - Geology, Ecology, and Landscapes 1(3): 173-183.

[7] Gu, Y. F., Ding, S. Y., Chen, H. S., Xing, Q. (2008): Ecophysiological responses and hyperspectral characteristics of winter wheat (Triticum aestivum) under drought stress. Acta Geologica Sinica 28(6): 2690-2697.

[8] Hashemi, N. (2017): Recognizing the potential of sustainable use of pasture resources in south khorasan province with approch of carrying capacity. - Environment Ecosystem Science 1(2): 09-12. 
[9] Hassan, S. R., Zaman, N. Q., Dahlan, I. (2017): Influence of seed loads on start up of modified anaerobic hybrid baffled (MAHB) reactor treating recycled paper wastewater. Engineering Heritage Journal 1(2): 05-09.

[10] Hejazi, S.M., Lotfi, F., Fashandi, H., Alirezazadeh, A. (2017): Serishm: an eco-friendly and biodegradable flame retardant for fabrics. Environment Ecosystem Science, 1(2): 0508 .

[11] Jia, K. L., Zhang, J. H. (2014): Impacts of different alkaline soil on canopy spectral characteristics of overlying vegetation. - Spectroscopy and Spectral Analysis 34(3): 782786.

[12] Liu, Q. S., Zhang, M., Ning, J. C., Liu, G. H., Fu, X., Huang, C. (2011): Hyperspectral vegetation indices of Suaeda Salsa in response to changes of soil chemical properties. Geography and Geo-Information Science 27(3): 86-89, 104.

[13] Lu, X., Liu, S. F., Zheng, L. Q. (2007): High spectral resolution data applied to identify plant stress response to heavy metal in mine site. - Science of Surveying and Mapping 32(2): 111-113.

[14] Ma, H. (2015): Research on Plant Feature Information Extraction Using Spectroscopy and Hyperspectral Imaging Technique. - China Agricultural University, Beijing.

[15] Pan, X., Pan, C. D., Hu, Z. Z. (2015): Leaf spectral characteristics and its sensitivity to N, $\mathrm{P}, \mathrm{K}$ in different fruit growth periods of Juglans regia 'Xinwen185'. - Xinjiang Agricultural Sciences 52(4): 628-636.

[16] Radan, A., Latifi, M., Moshtaghie, M., Ahmadi, M., Omidi, M. (2017): Determining the Sensitive Conservative Site in Kolah Ghazi National Park, Iran, In Order to Management Wildlife by Using GIS Software. Environment Ecosystem Science, 1(2): 13-15.

[17] Shannon, C. E. (1949): A mathematical theory of communication. - Bell System Technical Journal 27(3): 3-55.

[18] Tilley, D. R., Ahmed, M., Son, J. H., Badrinarayanan, H. (2007): Hyperspectral reflectance response of freshwater macrophytes to salinity in a brackish subtropical marsh. - Journal of Environmental Quality 36(3): 780-789.

[19] Vazdani, S., Sabzghabaei, G., Dashti, S., Cheraghi, M., Alizadeh, R., Hemmati, A. (2017): Fmea Techniques Used in Environmental Risk Assessment. Environment Ecosystem Science, 1(2): 16-18.

[20] Walburg, G., Bauer, M. E., Daughtry, C. S. T. (1982): Effects of nitrogen nutrition on the growth, yield, and reflectance characteristics of corn canopies. - Agronomy Journal 74(4): 677-683.

[21] Wang, Y., Zhang, H. W., Yang, H. M., Liu, G. F. (2009): Application of information entropy to regional allocation of waste water load. - Journal of Hydraulic Engineering 40(9): 1103-1107, 1115.

[22] Wei, Y., Gu, H. B., Xue, L., Jiang, Z. P., Zhou, J. X., Zheng, S. W., Cui, M., Yang, J. L. (2012): Review of studies on reclamation and ecological restoration of abandoned land of mine. - Science of Soil \& Water Conservation 10(2): 107-114.

[23] Wun, W. L., Chua, G. K., Chin, S. Y. (2017): Effect of palm oil mill effluent (pome) treatment by activated sludge. - Journal CleanWAS 1(2): 6-9.

[24] Xiao, H., Wang, M., Sheng, S. (2017): Spatial evolution of URNCL and response of ecological security: a case study on Foshan City. Geology, Ecology, and Landscapes, 1(3): 190-196.

[25] Yang, J., Xiang, M. S., Zhao, S. B. et al. (2014): Disaster Damaged Land Reclamation. Geological Publishing House, Beijing.

[26] Yang, K. M., Shi, G. Q., Liu, F., Sun, Y. Y., Wei, H. F. (2015): Research on spectral red edge parameters for monitoring corn leaves stressed by $\mathrm{Cu} 2+$. - Journal of Henan Agricultural Sciences 44(8): 160-164.

[27] Yang, R. C., Tian, H. Q., Li, F., Shi, S., Li, Z. (2017): Research on the SPAD values at different growth stages of sugar beet based on canopy hyperspectrum. - Journal of Arid Land Resources and Environment 37(7): 50-54. 
[28] Yang, S., Li, J., Song, Y. (2017): Application of surfactant Tween 80 to enhance Fenton oxidation of polycyclic aromatic hydrocarbons (PAHs) in soil pre-treated with Fenton reagents. Geology, Ecology, and Landscapes, 1(3): 197-204.

[29] Yang, W. N., Liu, E. Q., Chen, N., Liao, C. G. (2010): Remote sensing dynamic monitoring and driving force analysis of land use/cover changes in Chengdu. - Journal of Southwest Jiao Tong University 45(2): 185-190.

[30] Yu, J. J. (2012): Fast and Nondestructive Detection of Gray Mold on Tomato Plant Using High Spectrum Imaging Technology. - Zhe Jiang University, Hangzhou.

[31] Zhang, D. Y., Liu, R. Y., Song, X. Y., Xu, X. G., Huang, W. J., Zhu, D. Z., Wang, J. H. (2011): A field-based pushbroom imaging spectrometer for estimating chlorophyll content of maize. - Spectroscopy and Spectral Analysis 31(3): 771-775.

[32] Zhang, X. L., Zhang, Q. Q., Xu, T. X. et al.(2015): Amelioration of chemical and organic fertilizer on photo-inhibition of PS II at photosynthetic noon-break in mulberry leaves grew in saline-sodic soils. - Pratacultural Science 32(5): 745-753.

[33] Zhang, Y., Yang, Z. F., He, M. C., Hu, T. L. (2005): Analyses on evolution of urban complex ecosystem based on information entropy. - Acta Scientiae Circumstantiae 25(8): $1127-1134$.

[34] Zhao, Y. R., Yu, K. Q., Li, X. L., He, Y. (2014): Study on the SPAD visualization of pumpkin leaves based on hyperspectral imaging technology. - Spectroscopy and Spectral Analysis 34(5): 1378-1382.

[35] Zhong, B., Sun, G., Cheng, W., Zhang, N. N., Chen, C. (2016): Effects of Wenchuan earthquake on soil nutrient dynamics in forest. - Chinese Journal of Applied \& Environmental Biology 22(5): 773-779.

[36] Zou, X. B., Shi, J. Y., Hao, L. M., Zhao, J. W., Mao, H. P., Chen, Z. W., Li, Y. X., Mel, H. (2011): In vivo noninvasive detection of chlorophyll distribution in cucumber (Cucumis sativus) leaves by indices based on hyperspectral imaging. - Analytica Chimica Acta 706(1): 105-120.A. 